\title{
Men having sex with men serosorting with casual partners: who, how much, and what risk factors in Switzerland, 2007-2009
}

\author{
Stéphanie Lociciro, André Jeannin and Françoise Dubois-Arber ${ }^{*}$
}

\begin{abstract}
Background: Serosorting is practiced by men who have sex with men (MSM) to reduce human immunodeficiency virus (HIV) transmission. This study evaluates the prevalence of serosorting with casual partners, and analyses the characteristics and estimated numbers of serosorters in Switzerland 2007-2009.

Methods: Data were extracted from cross-sectional surveys conducted in 2007 and 2009 among self-selected MSM recruited online, through gay newspapers, and through gay organizations. Nested models were fitted to ascertain the appropriateness of pooling the datasets. Multiple logistic regression analysis was performed on pooled data to determine the association between serosorting and demographic, lifestyle-related, and health-related factors. Extrapolations were performed by applying proportions of various types of serosorters to Swiss population data collected in 2007.
\end{abstract}

Results: A significant and stable number of MSM (approximately 39\% in 2007 and 2009) intentionally engage in serosorting with casual partners in Switzerland. Variables significantly associated with serosorting were: gay organization membership ( $\mathrm{aOR}=1.67)$, frequent internet use for sexual encounters ( $\mathrm{aOR}=1.71$ ), having had a sexually transmitted infection (STI) at any time in the past 12 months $(\mathrm{aOR}=1.70)$, HIV-positive status $(\mathrm{aOR}=0.52)$, regularly frequenting sex-on-premises venues ( $\mathrm{aOR}=0.42$ ), and unprotected anal intercourse (UAI) with partners of different or unknown HIV status in the past 12 months ( $\mathrm{aOR}=0.22$ ). Approximately one-fifth of serosorters declared HIV negativity without being tested in the past 12 months; 15.8\% reported not knowing their own HIV status.

Conclusion: The particular risk profile of serosorters having UAI with casual partners (multiple partners, STI history, and inadequate testing frequency) requires specific preventive interventions tailored to HIV status.

Keywords: Sexual risk behaviour, Men who have sex with men, Serosorting, HIV, Switzerland

\section{Background}

A renewal of the human immunodeficiency virus (HIV) epidemic has been observed among men who have sex with men (MSM) in developed countries [1]. In Switzerland in 2010, although the proportion of recent infections (i.e., according to laboratory test methods, diagnosed within 6 months after the infection has occurred) had been decreasing among newly declared infections in MSM since 2008, the proportion of overall new HIV-positive tests

\footnotetext{
* Correspondence: Francoise.Dubois-Arber@chuv.ch

Institute of Social and Preventive Medicine (IUMSP), Lausanne University Hospital, Biopôle 2, Route de la Corniche 10, 1010 Lausanne, Switzerland
}

among MSM was still increasing to reach about $47 \%$ of all declared infections [2].

The increase in HIV testing may be one explanation for the re-emergence of the HIV epidemic among MSM [3]. However, in Switzerland, between 1994 and 2009, we observed a stable proportion of respondents reporting having been tested during the last 12 months, and an increase of 10 points in respondents having had at least one incident of unprotected anal intercourse (UAI) during the past 12 months with a partner of different or unknown HIV status [4].

Risk reduction practices other than condom use have been extensively studied [5-9]. Serosorting - choosing to 
have UAI with partners of the same HIV status-has been specifically studied [10-15], and has been considered to have a protective effect or convey a lower risk of HIV transmission in populations with a high prevalence and frequency of HIV testing [16-19]. However, the limits of this approach have also been demonstrated: serosorting may increase HIV transmission in populations with high rates of unrecognized and/or acute infection [10,20].

Serosorting can be perceived as a marker of freedom for MSM living with HIV, allowing them to believe that they can have unprotected sex without considering HIV transmission. However, it does not prevent the transmission of other sexually transmitted infections (STIs) [5], and disclosing one's own HIV positivity may be difficult.

For HIV-negative MSM, serosorting still carries the risk of being infected with HIV. First, serostatus may not be truthfully declared, either with a steady partner or with a casual partner. Authors highlighted that a majority of new HIV infections occurred within steady relationships [21]. Next, the knowledge of one's own or one's partner's HIV status may be inaccurate. Williamson et al. estimated that $41 \%$ of HIV-positive MSM enrolled in their study believed themselves to be HIV-negative [22]. One may genuinely believe himself to be HIV-negative, having had their last HIV test during the primary phase of infection within the seroconversion window [23].

This observational study focuses on the intentional practice of serosorters among MSM living in Switzerland who had anal intercourse with casual partners during the past 12 months without using a condom. The aims were:

a) to evaluate the prevalence of the practice in 2007 and 2009;

b) to analyse the characteristics of these specific serosorters; and

c) to estimate by extrapolation the number of MSM at risk of contracting HIV or other STIs in Switzerland as a result of serosorting with casual partners.

\section{Methods}

\section{Study population and data collection}

Data were obtained from the 2007 ( $\mathrm{N}=2953)$ and 2009 $(\mathrm{N}=1929)$ Swiss Gaysurvey, a repeated (nine times between 1987 and 2009) cross-sectional survey conducted in self-selected samples of MSM living in Switzerland. Respondents are recruited online with banners published on the main gay websites within the Switzerland Internet domain ("ch"), and through gay newspapers and gay or HIV/AIDS nongovernmental organizations (paper-andpencil version of the questionnaire).

The survey (pertaining to the Swiss HIV/STI behavioural surveillance system) used an anonymous self-administered questionnaire. The questionnaire has been used in its current form for most items since 1992. The main indicators that are used for surveillance were agreed upon at European level [24]. The items on sexual risk reduction practices were first introduced in the core questionnaire in 2007. The data collection methodology and the practical details of the questionnaire have been already presented elsewhere [25].

The questionnaire was reviewed by the Swiss Federal Office of Public Health, the Swiss Aids Foundation, and gay community leaders. The survey was approved by the ethical review board of the Faculty of Medicine and Biology at Lausanne University, Switzerland.

The questionnaire provided information about sociodemographic characteristics, sexual activity, HIV status (self-report), STI history, and preventive behaviours in different contexts of relationships (casual/steady partners and partners of different or unknown HIV status). The practice of serosorting was assessed with one question, referring to UAI with casual partners and stressing the participant's intention to reduce HIV transmission risks:

\section{"Over the past 12 months, did you ever practice anal intercourse without a condom and ask your partner if he was of the same HIV-status as you, in order to avoid HIV infection:" \\ - with steady partner (yes/no). \\ - with casual partners (yes/no).}

This question did not differentiate between insertive and receptive anal intercourse, and a casual partner was defined in the questionnaire as any sexual partner that the participant did not consider to be his steady partner. The word "serosorting" was not used in the questionnaire.

\section{Population}

Inclusion criteria for the studied population were: having had sex with a man at least once, having had a casual partner in the past 12 months, and having had anal intercourse without a condom with at least one casual partner in the past 12 months.

\section{Statistical analysis}

We proceeded first to a statistical description of the 2007 and 2009 data sets. Trends between these two years were tested with the chi-squared test of goodness of fit. To minimize Type I error, the significance level was determined using the Bonferroni adjustment procedure $(\alpha-$ level=0.003), yielding an overall level of 0.5.

Multiple logistic regression analysis was performed to study the interaction effects of interview mode and year of the survey with variables of interest. Interaction terms were built in order to make a decision concerning the possibility of merging the paper and web data sets, as well as the 2007 and 2009 data sets. 
The dependent variable was "to have practiced serosorting over the past 12 months" and the following variables were used as regressors: survey years (2007 vs. 2009), survey mode (paper vs. online questionnaire), age $(<25$; $25-49$; $\geq 50$ years of age), university degree, nationality, residence area (more than 100,000 inhabitants), membership in a gay organization, to currently have or having had a steady partner during the past 12 months, number of sexual partners with anal intercourse (AI) during the past 12 months (dichotomized at median of 6), regular visiting of sex-on-premises venues, frequent use of the internet for sexual encounters during the past 12 months, any STIs during the past 12 months, UAI with a partner of different or unknown HIV status during the past 12 months, an HIV test during the past 12 months, HIV status declared, and frequent substance use while having sex during the past 12 months.

To ascertain whether it was appropriate to pool the two datasets, three nested models were fitted: Model 1 included all factors plus the two selected interaction terms; Model 2 included all factors plus interaction terms with 'survey mode'; Model 3 included all factors plus interaction terms with 'survey years'. Likelihood-ratio tests were performed after the logistic regressions to compare Models 2 and 3 with Model 1.

Next, multiple logistic regression analysis was performed on pooled data to determine the association between serosorting and demographic, lifestyle-related, and health-related factors. Odds ratios and 95\% confidence intervals were calculated for each of predictor mentioned above.

Finally, the number of MSM at various levels of risk for HIV as a result of serosorting with casual partners was estimated through extrapolation by applying proportions of different types of serosorters found in the pooled Gaysurveys 2007 and 2009 to Swiss population data collected in the Swiss Health Survey 2007. This survey defines MSM on the basis of self-reported types of sexual partners interacted with during one's lifetime, using a modified Kinsey indicator [26]. Two definitions of MSM were chosen: a restrictive definition that includes men who have sex only with men, mainly with men, and with as many men as women $\left(\mathrm{N}_{\text {Swiss }}=33,700\right)$; and a more inclusive definition that includes all men who have had sex with a man at least once in their lifetime $\left(\mathrm{N}_{\text {Swiss }}=70,300\right)$. We estimated several proportions of MSM at risk in Switzerlandwith their 95\% confidence interval-according to different types of situations. To define these diverse risk situations, we used the following variables: had an HIV test during the past 12 months, and (for HIV-positive MSM) the viral load and occurrence of STIs in the past 12 months. Confidence intervals were obtained for each proportion and used to evaluate the minimum and maximum number of MSM involved for each type of situation.
Data were analysed using the statistical package STATA 11.1 (StataCorp LP, College Station, Texas, USA).

\section{Results}

Population

Figure 1 presents the details for each survey year with different filters applied. Of 4882 MSM who answered in 2007 and 2009 (aggregated), 13.3\% $(\mathrm{n}=647)$ have had UAI with casual partners in the past 12 months. Among them, 38.2\% $(\mathrm{N}=247)$ used serosorting as a harm reduction practice.

\section{Respondents' characteristics}

Respondents who had UAI with casual partners during the past 12 months $\left(\mathrm{N}_{2007}=416 ; \mathrm{N}_{2009}=231\right)$ are presented in Table 1. Approximately two-fifths practiced serosorting (2007: 37.7\%; 2009: 39.0\%). This difference was not statistically significant. The two samples varied little: there were more non-Swiss nationals in 2009 (27.7\%) than in 2007 (16.6\%, p $=0.001)$, and the proportion of respondents reporting an STI in the past 12 months was higher in 2009 (2009: 24.2\%; 2007: 17.3\%, $\mathrm{p}=0.003$ ).

\section{Multivariate analysis: predictors of serosorting Non-responses management}

Non-responses rates were inferior or equal to 5\% for all variables (Table 1), and were therefore merged with respondents having answered 'No' to the question for the multivariate analysis. Regarding the 'age' and 'number of sexual partners with UAI' variables, non-responses were replaced with median age (36 years) and median number of partners ( 2 partners).

\section{Logistic regression models and $L R$ tests}

Multivariate logistic regression was run for Models 1, 2, and 3. No significant interactions were observed according to the LR test between Models 1 and $2\left(\operatorname{LR} \chi^{2}(14)=14.6\right.$; $\mathrm{p}=0.406)$ or between Models 1 and $3\left(\mathrm{LR} \chi^{2}(14)=18.1\right.$; $\mathrm{p}=0.202$ ). Adding interaction terms as predictor variables did not result in a statistically significant improvement in model fit. Thus, adding mode and year interaction terms as predictor variables did not result in a statistically significant improvement in model fit and a final, simpler model (Model 4) composed exclusively of regressors without any interaction terms was retained. On this basis, the two samples (2007 and 2009) were pooled for further analysis.

Six variables were significantly associated $(\mathrm{p}<0.05)$ with serosorting in this final Model 4 (Table 2). Gay organization membership ( $\mathrm{aOR}=1.67$ ), frequent internet use for sexual encounters $(\mathrm{aOR}=1.71)$, and having had an STI in the past twelve months $(\mathrm{aOR}=1.70)$ were factors positively associated with serosorting. Regarding reported HIV status, only positive HIV status was significantly and negatively associated with serosorting $(\mathrm{aOR}=0.52)$. Two other factors were significantly negatively associated with serosorting: regularly 


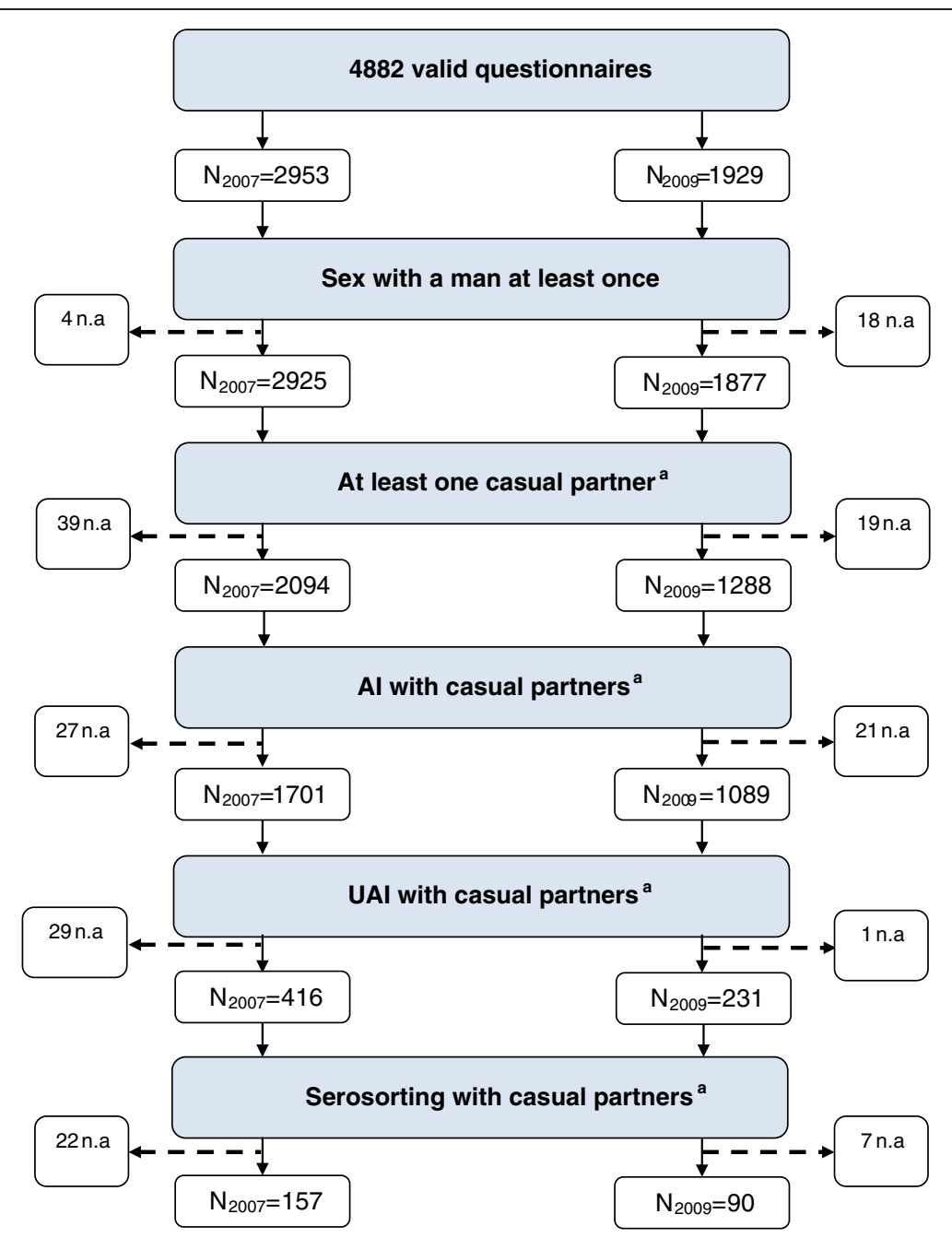

Figure 1 Filters applied for analyses: population under study.

frequenting sex-on-premises venues $(\mathrm{aOR}=0.42)$, and UAI with partners of different or unknown HIV status in the past 12 months $(\mathrm{aOR}=0.22)$.

\section{Estimates of the number of MSM at risk of contracting HIV in Switzerland as a result of serosorting with casual partners}

Because the year and survey mode did not provide additional information about the practice of serosorting, data from 2007 and 2009 and the paper and web surveys were pooled for this analysis $(\mathrm{N}=4882)$ to further investigate the practice with respect to the respondent's HIV status, and (for HIV-positive respondents) current viral load and STI occurrence, during the past 12 months. Among the 1929 respondents in 2009, 517 (27\%) had participated in the 2007 survey.

Table 3 presents the extrapolated numbers of MSM at risk of contracting HIV as a result of serosorting in Switzerland. They have been determined according to the percentage and confidence interval of MSM concerning different scenarios within the pooled Gaysurvey data. The mean number of sexual partners with whom respondents have had AI during the past 12 months was calculated and presented with standard deviation to develop a picture of the number of respondents potentially concerned by this risk-taking. Respondents who reported having more than 80 partners were considered outliers and excluded from this calculation.

The extrapolated data show that a minimum of 4150 and a maximum of 10,008 MSM have had UAI with a casual partner in the past 12 months, among whom between 1503 and 4015 practiced serosorting.

Of all serosorters, $17.8 \%(221<\mathrm{N}<849)$ reported being HIV-positive. They were analysed according to two parameters that would represent increased risk of HIV transmission: reporting having had a detectable viral load (or not), and reporting having had an STI (or not). Between 19 and 208 MSM in Switzerland reported having had a 
Table 1 Univariate analysis: characteristics of participants ${ }^{\dagger}$

\begin{tabular}{|c|c|c|c|c|c|c|c|}
\hline Serosorting & \multicolumn{2}{|c|}{$\begin{array}{c}2007 \\
\mathrm{~N}=416(\%)\end{array}$} & \multicolumn{2}{|c|}{$\begin{array}{c}2009 \\
N=231(\%)\end{array}$} & \begin{tabular}{|c|} 
P-value \\
0.412 \\
\end{tabular} & \multicolumn{2}{|c|}{$\begin{array}{l}\text { Pooled data } \\
\mathrm{N}=647(\%)\end{array}$} \\
\hline Yes & 157 & $(37.7)$ & 90 & (39.0) & & 247 & $(38.2)$ \\
\hline No & 237 & $(57.0)$ & 134 & $(58.0)$ & & 371 & $(57.3)$ \\
\hline No answer & 22 & $(5.3)$ & 7 & $(3.0)$ & & 29 & $(4.5)$ \\
\hline Age & & & & & 0.200 & & \\
\hline$<25 \mathrm{yr}$ & 82 & (19.7) & 49 & $(21.2)$ & & 131 & $(20.2)$ \\
\hline $25-49 \mathrm{yr}$. & 282 & $(67.8)$ & 150 & $(64.9)$ & & 432 & $(66.8)$ \\
\hline$\geq 50 \mathrm{yr}$ & 46 & (11.1) & 32 & (13.9) & & 78 & $(12.1)$ \\
\hline No answer & 6 & $(1.4)$ & 0 & - & & 6 & $(0.9)$ \\
\hline Survey mode & & & & & 0.100 & & \\
\hline Paper & 149 & $(35.8)$ & 68 & (29.4) & & 217 & (33.5) \\
\hline Internet & 267 & $(64.2)$ & 163 & (70.6) & & 430 & $(66.5)$ \\
\hline University degree & & & & & 0.574 & & \\
\hline Yes & 185 & $(44.5)$ & 110 & $(47.6)$ & & 295 & $(45.6)$ \\
\hline No & 230 & $(55.3)$ & 121 & $(52.4)$ & & 351 & (54.3) \\
\hline No answer & 1 & $(0.3)$ & 0 & - & & 1 & $(0.2)$ \\
\hline Nationality & & & & & 0.001 & & \\
\hline Swiss national & 336 & $(80.8)$ & 166 & (71.9) & & 502 & $(77.6)$ \\
\hline Non Swiss national & 69 & (16.6) & 64 & $(27.7)$ & & 133 & (20.6) \\
\hline No answer & 11 & $(2.6)$ & 1 & $(0.4)$ & & 12 & (1.9) \\
\hline Residence area $>100,000$ inhabitants & & & & & 0.297 & & \\
\hline Yes & 174 & $(41.8)$ & 86 & $(37.2)$ & & 260 & $(40.2)$ \\
\hline No & 241 & $(57.9)$ & 143 & (61.9) & & 384 & $(59.4)$ \\
\hline No answer & 1 & $(0.2)$ & 2 & $(0.9)$ & & 3 & $(0.5)$ \\
\hline Gay organization & & & & & 0.602 & & \\
\hline Yes & 60 & $(14.4)$ & 38 & $(16.5)$ & & 98 & $(15.1)$ \\
\hline No & 355 & (85.3) & 193 & (83.6) & & 548 & $(84.7)$ \\
\hline No answer & 1 & $(0.2)$ & 0 & - & & 1 & $(0.2)$ \\
\hline Steady partner ${ }^{a}$ & & & & & 0.038 & & \\
\hline Yes & 172 & $(41.4)$ & 116 & $(50.2)$ & & 288 & $(44.5)$ \\
\hline No & 240 & $(57.7)$ & 115 & $(49.8)$ & & 355 & $(54.9)$ \\
\hline No answer & 4 & $(1.0)$ & 0 & - & & 4 & $(0.6)$ \\
\hline Number of sexual partners with $\mathrm{Al}^{\mathrm{a}}$ & & & & & 0.219 & & \\
\hline None & 9 & $(2.2)$ & 2 & $(0.9)$ & & 11 & $(1.7)$ \\
\hline $1-5$ partners & 200 & $(48.1)$ & 102 & $(44.2)$ & & 302 & $(46.7)$ \\
\hline$\geq 6$ partners & 207 & $(49.8)$ & 126 & $(54.6)$ & & 333 & $(51.5)$ \\
\hline No answer & 0 & - & 1 & $(0.4)$ & & 1 & $(0.2)$ \\
\hline Regularly frequenting sex-on-premises venues ${ }^{a}$ & & & & & 0.659 & & \\
\hline Yes & 82 & $(19.7)$ & 47 & $(20.4)$ & & 129 & $(19.9)$ \\
\hline No & 322 & $(77.4)$ & 180 & $(77.9)$ & & 502 & (77.6) \\
\hline No answer & 12 & $(2.9)$ & 4 & $(1.7)$ & & 16 & $(2.5)$ \\
\hline
\end{tabular}


Table 1 Univariate analysis: characteristics of participants ${ }^{\dagger}$ (Continued)

\begin{tabular}{|c|c|c|c|c|c|c|c|}
\hline Frequent use of the internet for sexual encounters ${ }^{a}$ & & & & & 0.558 & & \\
\hline Yes & 178 & $(42.8)$ & 109 & $(47.2)$ & & 287 & $(44.4)$ \\
\hline No & 232 & (55.8) & 119 & (51.5) & & 351 & $(54.3)$ \\
\hline No answer & 6 & $(1.4)$ & 3 & $(1.3)$ & & 9 & (1.4) \\
\hline Sexually transmitted infections ${ }^{a}$ & & & & & 0.003 & & \\
\hline Yes & 72 & $(17.3)$ & 56 & $(24.2)$ & & 128 & $(19.8)$ \\
\hline No & 330 & $(79.3)$ & 175 & (75.8) & & 505 & $(78.1)$ \\
\hline No answer & 14 & $(3.4)$ & 0 & - & & 14 & (2.2) \\
\hline UAI with partners of different or unknown HIV status ${ }^{\mathrm{a}}$ & & & & & 0.510 & & \\
\hline Yes & 295 & (70.9) & 155 & $(67.1)$ & & 450 & (69.6) \\
\hline No & 118 & (28.4) & 75 & (32.5) & & 193 & $(29.8)$ \\
\hline No answer & 3 & $(0.7)$ & 1 & $(0.4)$ & & 4 & (0.6) \\
\hline HIV test ${ }^{a}$ & & & & & 0.087 & & \\
\hline Yes & 177 & (42.6) & 106 & $(45.9)$ & & 283 & $(43.7)$ \\
\hline No & 231 & $(55.5)$ & 125 & $(54.1)$ & & 356 & $(55.0)$ \\
\hline No answer & 8 & $(1.9)$ & 0 & - & & 8 & $(1.2)$ \\
\hline HIV status declared & & & & & 0.021 & & \\
\hline Unknown & 94 & (22.6) & 62 & (26.8) & & 156 & $(24.1)$ \\
\hline HIV negative & 256 & $(61.5)$ & 117 & $(50.7)$ & & 373 & $(57.7)$ \\
\hline HIV positive/Aids & 66 & $(15.9)$ & 52 & $(22.5)$ & & 118 & $(18.2)$ \\
\hline Frequent substance use while having sex ${ }^{a}$ & & & & & 0.054 & & \\
\hline Yes & 119 & (28.6) & 83 & (35.9) & & 202 & $(31.2)$ \\
\hline No & 297 & $(71.4)$ & 148 & $(64.1)$ & & 445 & (68.8) \\
\hline
\end{tabular}

${ }^{\dagger}$ Based on inclusion criteria: UAI with casual partners in the past 12 months.

a in the past 12 months.

${ }^{b}$ Among respondents who had a steady partner and had Al with him in the past 12 months $\left(N_{2007}=138\right.$ and $N_{2009}=116$.)

Al Anal Intercourse, UAl Unprotected Anal Intercourse.

detectable viral load and STI. Most of the HIV-positive serosorters had an undetectable viral load and no STI $(67<\mathrm{N}<352)$, i.e. no increased risk of HIV/STI transmission [27].

Of all serosorters, 66.4\% $(968<\mathrm{N}<2744)$ declared that they were HIV-negative. They were considered from the perspective of being tested for HIV in the past 12 months (i.e., having more accurate knowledge of their own HIV status). Data indicated that $45.3 \%(638<\mathrm{N}<$ 1936) of the serosorters had been tested recently and were HIV-negative. However, 21.1\% $(268<\mathrm{N}<980)$ declared that they were HIV-negative even though they had not been tested in the past 12 months, and another $15.8 \%(192<\mathrm{N}<767)$ MSM serosorted while they had not been recently tested for HIV or did not know their HIV status (i.e., with a higher risk of potentially transmitting HIV to their casual partners).

The mean number of sexual partners was 18( \pm 2$)$ among HIV-positive serosorters and 10( \pm 1$)$ among HIV-negative serosorters; the data suggests that a large population of MSM are involved in this practice.

\section{Discussion}

A significant and stable number of MSM (approximately $39 \%$ in 2007 and 2009) were classified as engaging in serosorting with casual partners in Switzerland. Estimates concerning the number of persons involved in various levels of risk were provided.

Risk reduction practices are often analysed in publications as several overlapping questions regarding respondents' sexual behaviour: the question of UAI with steady and/or casual partners, paired with the presumed or proven serostatus of the respondent and the supposed serostatus of the respondent's partners. Serosorting assumes that the protagonists have disclosed their respective HIV statuses beforehand with the explicit aim of avoiding HIV infection. However, this intention concept is often not made explicit in the serosorting definition or is entirely missing from questionnaires. The Swiss GaySurvey focused on risk reduction practices with steady and casual partners in the last two survey waves [4], and asked specifically whether the respondent acted with the purpose of preventing HIV transmission. The word "serosorting" 
Table 2 Multivariate logistic regression: factors associated with serosorting

\begin{tabular}{rrrr}
\hline & aOR & $95 \% \mathrm{Cl}$ & P-value \\
\hline Survey year & & & \\
2007 & 1 & & 0.982 \\
2009 & 1.00 & $0.69-1.46$ &
\end{tabular}

Survey mode

Paper 1

$\begin{array}{llll}\text { Internet } & 0.83 & 0.55-1.25 & 0.367\end{array}$

Age

$\begin{array}{rrrr}<25 \text { yr. } & 0.83 & 0.50-1.36 & 0.457 \\ 25-49 \text { yr. } & 1 & & \\ \geq 50 \text { yr. } & 0.72 & 0.40-1.30 & 0.275\end{array}$

University degree

Yes

0.90

$0.61-1.32$

No

1

Nationality

Non-Swiss national

0.98

$0.62-1.55$

Swiss national

1

Residence area $>100,000$ inhabitants

$\begin{array}{rrr}\text { Yes } & 1.22 & 0.84-1.77 \\ \text { No } & 1 & \end{array}$

Gay organization

Yes

1.67

$1.02-2.73$

No

1

Steady partner ${ }^{\mathrm{a}}$

Yes $\quad 0.75$

Number of sexual partners with $\mathrm{Al}^{\mathrm{a}}$

$1-5$ partners

$\geq 6$ partners

1.32

$0.88-1.99$

0.181

Regularly frequenting sex-on-premises venues ${ }^{\mathrm{a}}$

$\begin{array}{rrr}\text { Yes } & \mathbf{0 . 4 2} & \mathbf{0 . 2 6 - 0 . 7 0 8} \\ \text { No } & 1 & \end{array}$

Frequent use of the internet for sexual encounters ${ }^{\mathrm{a}}$

$\begin{array}{ccc}\text { Yes } & \mathbf{1 . 7 1} & \mathbf{1 . 1 6 - 2 . 5 0} \\ \text { No } & 1 & \end{array}$

Sexually transmitted infections ${ }^{a}$

$\begin{array}{lrr}\text { Yes } & \mathbf{1 . 7 0} & \mathbf{1 . 0 7 - 2 . 6 9} \\ \text { No } & 1 & \end{array}$

UAI with partners of different or unknown HIV status ${ }^{a}$

$\begin{array}{lrr}\text { Yes } & \mathbf{0 . 2 2} & \mathbf{0 . 1 4}-\mathbf{0 . 3 2} \\ \text { No } & 1 & \end{array}$

Table 2 Multivariate logistic regression: factors associated with serosorting (Continued)

\begin{tabular}{crcc}
\hline HIV test $^{\mathbf{a}}$ & & & \\
Yes & 1.47 & $0.98-2.19$ & 0.063 \\
No & 1 & & \\
HIV status declared & & & 0.256 \\
Unknown & 0.74 & $0.44-1.24$ & \\
HIV negative & 1 & & $\mathbf{0 . 0 1 3}$ \\
HIV positive/Aids & $\mathbf{0 . 5 2}$ & $\mathbf{0 . 3 1 - 0 . 8 7}$ &
\end{tabular}

Frequent substance use while having sex ${ }^{a}$

$\begin{array}{rrrr}\text { Yes } & 1.01 & 0.67-1.52 & 0.958 \\ \text { No } & 1 & & \end{array}$

The reference category for the dependant variable is "having practised serosorting". Bold denotes adjusted odds ratio significant at the 0.003 level.

${ }^{a}$ In the past 12 months.

${ }^{\mathrm{b}}$ Among respondents who had a steady partner and had Al with him in the past 12 months $\left(\mathrm{N}_{2007}=151\right.$ and $\left.\mathrm{N}_{2009}=117\right)$.

Al: Anal Intercourse; aOR: adjusted odds ratio; Cl: confidence interval.

itself was deliberately not used in the questionnaire in order not to influence the respondents.

Multivariate analysis tends to indicate that serosorting may be practiced as a structured, planned strategy, when we consider factors negatively and positively associated with serosorting. MSM who reported themselves as HIVpositive and that they have had UAI with partners of different or unknown HIV status are indeed less likely to engage in serosorting. Regularly visiting sex-on-premises venues is also negatively associated with serosorting. This negative association might be explained by the difficulty of disclosing one's HIV status in places (e.g., backrooms, darkrooms, or saunas) where verbal interactions are not encouraged [28].

Serosorting was positively associated with belonging to a gay organisation, possibly owing to existing debates on risk reduction within these organisations in Switzerland, and more informed choices resulting from these discussions. Similarly, frequent use of the internet to select partners is associated with serosorting. Partner selection through the internet may seem an appropriate method a priori because it can be easier to declare one's HIV status anonymously, rather than face-to-face, or it may simply be faster to find a partner of same HIV status. However, these conclusions contrast with findings from Berry et al., who showed that internet usage was significantly associated with an increased likelihood of UAI with potentially discordant partners among HIV-negative MSM [29].

As expected, our data revealed a positive association between serosorting and reporting an STI in the last 12 months [30]. Serosorting was much more practiced by HIV-negative men tested in the past 12 months than by HIV-positive MSM (45.3\% vs. 17.8\%). This result was expected because of the wording of the original question. However, $21.1 \%$ of serosorters declared themselves to be 
Table 3 Serosorting: extrapolated country MSM population

\begin{tabular}{|c|c|c|c|c|c|c|c|c|c|c|c|}
\hline & \multirow{2}{*}{\multicolumn{7}{|c|}{ Gaysurvey sample data }} & \multicolumn{4}{|c|}{ Extrapolated to country MSM population (17-74 yr.) } \\
\hline & & & & & & & & \multicolumn{2}{|c|}{$\begin{array}{l}\text { a) Restricted definition (sex } \\
\text { only with men, mainly with } \\
\text { men, and with as many } \\
\text { women as men, lifetime) }\end{array}$} & \multicolumn{2}{|c|}{$\begin{array}{l}\text { b) Enlarged definition } \\
\text { (at least one partner } \\
\text { of same sex, lifetime) }\end{array}$} \\
\hline & $\mathbf{N}$ & $\%$ & \multicolumn{3}{|c|}{$\mathrm{Cl} 95 \%^{\mathrm{c}}$} & $\begin{array}{c}\text { \% Among } \\
\text { Serosorters \% }\end{array}$ & $\begin{array}{l}\text { Mean number of sexual } \\
\text { partners with } \mathrm{Al}^{\mathrm{d}}\end{array}$ & $\mathrm{N}$ & $\operatorname{Min}_{\mathrm{a}} / \max _{\mathrm{a}}$ & $\mathbf{N}$ & $\operatorname{Min}_{b} / \max _{b}$ \\
\hline Pooled Gaysurvey data (2007-2009) & 4882 & 100 & & & & & & 33,700 & & & 70,300 \\
\hline UAI with casual partners ${ }^{a}$ & 647 & 13.3 & 12.3 & - & 14.2 & & $11 \pm 1$ & 4466 & $4150 / 4798$ & 9317 & $8656 / 10,008$ \\
\hline Serosorting with casual partners ${ }^{\mathrm{b}}$ & 247 & 5.1 & 4.5 & - & 5.7 & $N=247$ & $11 \pm 1$ & 1705 & $1503 / 1925$ & 3557 & $3136 / 4015$ \\
\hline \multicolumn{12}{|l|}{ Serostatus declared } \\
\hline HIV-positive & 44 & 0.9 & 0.7 & - & 1.2 & 17.8 & $18 \pm 2$ & 304 & $221 / 407$ & 634 & $461 / 849$ \\
\hline Detectable viral load and No STI ${ }^{\mathrm{e}}$ & 10 & 0.2 & 0.1 & - & 0.4 & 4.0 & $17 \pm 5$ & 69 & $33 / 127$ & 144 & $69 / 265$ \\
\hline Undetectable viral load and No STI & 15 & 0.3 & 0.2 & - & 0.5 & 6.1 & $18 \pm 4$ & 104 & $67 / 169$ & 216 & $141 / 352$ \\
\hline Undetectable viral load and STI & 12 & 0.2 & 0.1 & - & 0.4 & 4.9 & $15 \pm 4$ & 83 & $43 / 145$ & 173 & $89 / 302$ \\
\hline Detectable viral load and STI & 7 & 0.1 & 0.1 & - & 0.3 & 2.8 & $24 \pm 5$ & 48 & 19/99 & 101 & $41 / 208$ \\
\hline HIV-negative & 164 & 3.4 & 2.9 & - & 3.9 & 66.4 & $10 \pm 1$ & 1132 & $968 / 1316$ & 2362 & $2019 / 2744$ \\
\hline Tested in the past 12 months & 112 & 2.3 & 1.9 & - & 2.8 & 45.3 & $11 \pm 1$ & 773 & $638 / 928$ & 1613 & $1331 / 1936$ \\
\hline Not tested in the past 12 months & 52 & 1.1 & 0.8 & - & 1.4 & 21.1 & $8 \pm 1$ & 359 & $268 / 470$ & 749 & $560 / 980$ \\
\hline N.A, D.K, Not tested ${ }^{f}$ & 39 & 0.8 & 0.6 & - & 1.1 & 15.8 & $10 \pm 2$ & 269 & $192 / 367$ & 562 & $400 / 767$ \\
\hline
\end{tabular}

a: Unprotected anal intercourse (UAI) in the past 12 month.
b: Among respondents who had UAl with casual partners in the past 12 months $(N=647)$.

c: Confidence interval (Cl) calculated with the exact binomial distribution.

$\mathrm{d}$ : Anal intercourse in the past 12 months.

e: Sexually transmitted infections (STIs) in the past 12 months

f: N.A: No answer; D.K: Don't know. 
HIV-negative without having been tested during the past 12 months $(268<\mathrm{N}<980)$, and $15.8 \%$ reported not knowing their HIV status $(192<\mathrm{N}<767)$ and may be considered at risk of being infected with HIV or of infecting other people with HIV. This finding is disturbing, particularly regarding the high mean number of sexual partners reported.

The particular risk profile of these serosorters who have UAI with casual partners (multiple partners, UAI with partners of different or unknown status, STI history, and partially inadequate testing frequency) requires preventive interventions tailored to HIV status.

Our study focused on MSM who have casual male partners, and does not go into detail about any relationship with a steady partner among these men. Moreover, a certain proportion of MSM serosorters also have sex with women. We can make the assumption that the practice of serosorting carries a risk for both sexes, as well as for both homosexual and heterosexual couples. This component should also be taken into account within prevention programmes.

Our results confirm those of several authors, notably Heymer et al., who concluded that serosorting has a real potential to increase risk and should not be promoted as a public-health strategy [31]. HIV testing alone is not a panacea, and frequent testing for HIV and other STIs, behavioural interventions, and emphasis on primary infections should be jointly promoted.

Our study has limitations: Gaysurvey data are not representative of the entire MSM population. The broad dissemination of our questionnaire likely attenuated selection bias. However, this method may overestimate levels of risky behavior, given that several of the sites or newspapers used for recruitment are also used to contact partners. We also do not know how often serosorting occurs, or the absolute number of partners with whom serosorters engaged in serosorting. MSM who responded to Gaysurvey may be numerous to be concerned by serosorting; the intensity of risk remains unknown.

We did not exclude from the 2009 dataset those who reported having participated in 2007. The proportion of serosorters in 2009 who had reported having participated in the 2007 survey was not significantly different from the non-serosorters in this situation (respectively $23.2 \%$ and $25 \%)$. Furthermore, most of the variables associated with serosorting were variables measuring behaviours reported over a period of 12 months (last 12 months).

The quality of the extrapolation of the numbers of serosorters to the MSM population in Switzerland is dependent upon the quality of the GaySurvey samples used in the computations, which remains unknown. However, we also relied on data from a health survey in the general population, with a restricted and an enlarged definition of MSM, to compute these extrapolated estimates. That survey is a random probability survey which does not suffer from the same weaknesses as GaySurvey and is uncorrelated to it.

\section{Conclusion}

Despite these limitations we feel that our study brings careful estimates that may be useful to plan preventive activities.

\section{Abbreviations}

MSM: Men who have sex with men; HIV: Human immunodeficiency virus; STI: Sexually transmitted infection; UAI: Unprotected anal intercourse.

\section{Competing interests}

The authors declare that they have no competing interests.

\section{Authors' contributions}

It is an original article-not submitted elsewhere-in which all the authors have contributed significantly: SL data collection, data analysis, writing of the article, AJ, survey conceptualization, data analysis supervision, participation in the writing and final approval, FDA, conceptualization and direction of the study, participation in the writing and final approval. All authors read and approved the final manuscript.

\section{Acknowledgement}

Warm thanks to the participants who responded to the survey; and to the associations, establishments, Web sites, and magazines that distributed the questionnaire.

This study was funded by the Swiss Federal office of Public Health, grant 04.000158 2.24.01.-744.

Received: 20 February 2013 Accepted: 4 September 2013

Published: 11 September 2013

\section{References}

1. Joint United Nations Programme on HIV/AIDS (UNAIDS): Global report: UNAIDS report on the global AIDS epidemic 2010; 2010.

2. Office féderal de la santé publique (OFSP): VIH/sida en Suisse: données au 31 décembre 2010. Bulletin de l'Office Fédéral de la Santé Publique 2011, 6/11:103-105.

3. Sullivan PS, Hamouda O, Delpech V, Geduld JE, Prejean J, Semaille C, Kaldor J, Folch C, Op de Coul E, Marcus U, et al: Reemergence of the HIV epidemic among men who have sex with men in North America, Western Europe, and Australia, 1996-2005. Ann Epidemio/ 2009, 19(6):423-431.

4. Lociciro S, Jeannin A, Dubois-Arber F: Les comportements face au VIH/SIDA des hommes qui ont des relations sexuelles avec des hommes: résultats de Gaysurvey 2009. Raisons de santé 163. Lausanne: Institut universitaire de médecine sociale et préventive; 2010.

5. Hart GJ, Elford J: Sexual risk behaviour of men who have sex with men: emerging patterns and new challenges. Curr Opin Infect Dis 2010, 23:39-44.

6. Lattimore S, Thornton A, Delpech V, Elford J: Changing patterns of sexual risk behavior among London gay men: 1998-2008. Sex Transm Dis 2011, 38(3):221-229.

7. Parsons JT, Schrimshaw EW, Wolitski RJ, Halkitis PN, Purcell DW, Hoff CC, Gomez CA: Sexual harm reduction practices of HIV-seropositive gay and bisexual men: serosorting, strategic positioning, and withdrawal before ejaculation. AIDS 2005, 19(Suppl 1):S13-S25.

8. Halkitis PN, Moeller RW, Pollock JA: Sexual practices of gay, bisexual, and other nonidentified MSM attending New York City gyms: patterns of serosorting, strategic positioning, and context selection. J Sex Res 2008, 45(3):253-261.

9. McFarland W, Chen YH, Nguyen B, Grasso M, Levine D, Stall R, Colfax G, Robertson T, Truong HM, Raymond HF: Behavior, intention or chance? a longitudinal study of HIV seroadaptive behaviors, abstinence and condom use. AIDS Behav 2012, 16(1):121-131.

10. Jin F, Crawford J, Prestage GP, Zablotska I, Imrie J, Kippax SC, Kaldor JM, Grulich AE: Unprotected anal intercourse, risk reduction behaviours, and subsequent HIV infection in a cohort of homosexual men. AIDS 2009, 23(2):243-252.

11. Golden MR, Stekler J, Hughes JP, Wood RW: HIV serosorting in men who have sex with men: is it safe? J Acquir Immune Defic Syndr 2008, 49(2):212-218. 
12. Eaton LA, Kalichman SC, O'Connell DA, Karchner WD: A strategy for selecting sexual partners believed to pose little/no risks for HIV: serosorting and its implications for HIV transmission. AIDS Care 2009, 21(10):1279-1288.

13. McFarland W, Chen YH, Raymond HF, Nguyen B, Colfax G, Mehrtens J, Robertson T, Stall R, Levine D, Truong HM: HIV seroadaptation among individuals, within sexual dyads, and by sexual episodes, men who have sex with men, San Francisco, 2008. AIDS Care 2011, 23(3):261-268.

14. Snowden JM, Raymond HF, McFarland W: Seroadaptive behaviours among men who have sex with men in San Francisco: the situation in 2008. Sex Transm Infect 2011, 87(2):162-164.

15. Zablotska IB, Imrie J, Prestage G, Crawford J, Rawstorne P, Grulich A, Jin F, Kippax S: Gay men's current practice of HIV seroconcordant unprotected anal intercourse: serosorting or seroguessing? AIDS Care: Psychol Sociomedi Aspects of AIDS/HIV 2009, 21(4):501-510.

16. Philip SS, Yu X, Donnell D, Vittinghoff E, Buchbinder S: Serosorting is associated with a decreased risk of HIV seroconversion in the EXPLORE study cohort. PLoS ONE 2010, 5(9):e12662. Electronic Resource.

17. Xia Q, Molitor F, Osmond DH, Tholandi M, Pollack LM, Ruiz JD, Catania JA: Knowledge of sexual partner's HIV serostatus and serosorting practices in a California population-based sample of men who have sex with men. AIDS 2006, 20(16):2081-2089.

18. Cassels S, Menza TW, Goodreau SM, Golden MR: HIV serosorting as a harm reduction strategy: evidence from Seattle. Washington AIDS 2009, 23(18):2497-2506.

19. Jin F, Prestage GP, Templeton DJ, Poynten IM, Donovan B, Zablotska I, Kippax SC, Mindel A, Grulich AE: The impact of HIV seroadaptive behaviors on sexually transmissible infections in HIV-negative homosexual men in Sydney. Australia Sex Transm Dis 2012, 39(3):191-194.

20. Pinkerton SD: Acute HIV infection increases the dangers of serosorting. Am J Prev Med 2008, 35(2):184.

21. Sullivan PS, Salazar L, Buchbinder S, Sanchez TH: Estimating the proportion of HIV transmissions from main sex partners among men who have sex with men in five US cities. AIDS 2009, 23(9):1153-1162

22. Williamson LM, Dodds JP, Mercey DE, Hart GJ, Johnson AM: Sexual risk behaviour and knowledge of HIV status among community samples of gay men in the UK. AIDS 2008, 22(9):1063-1070.

23. Mackellar DA, Valleroy LA, Behel S, Secura GM, Bingham T, Celentano DD, Koblin BA, LaLota M, Shehan D, Thiede H, et al: Unintentional HIV exposures from young men who have sex with men who disclose being HIV-negative. AIDS 2006, 20(12):1637-1644.

24. Bochow M, Chiarotti F, Davies P, Dubois-Arber F, Dür W, Fouchard J, Gruet F, McManus T, Markert S, Sandfort T, et al: Sexual behaviour of gay and bisexual men in eight European countries. AIDS Care 1994, 6(5):533-549.

25. Balthasar H, Jeannin A, Lociciro S, Dubois-Arber F: Intentional risk reduction practices of men in Switzerland who have anal intercourse with casual male partners. J Acquir Immune Defic Syndr 2010, 54(5):542-547.

26. Wellings $\mathrm{K}$, Field J, Johnson AM, Wadsworth J: Sexual behaviour in Britain: the national survey of sexual attitudes and lifestyles. London: Penguin Books; 1994

27. Vernazza P, Hirschel B, Bernasconi E, Flepp M: HIV- infizierte Menschen ohne andere STD sind unter wirksamer antiretroviraler Therapie sexuell nicht infektiös [HIV-infected people free of other STDs are sexually not infectious on effective antiretroviral therapy]. Schweizerische Arztezeitung Bulletin des Medecins Suisses Bollettino dei Medici Svizzeri 2008, 89:165-169.

28. Rietmeijer CA, Lloyd LV, McLean C: Discussing HIV serostatus with prospective sex partners: a potential HIV prevention strategy among high-risk men who have sex with men. Sex Transm Dis 2007, 34(4):215-219.

29. Berry M, Raymond HF, Kellogg T, McFarland W: The internet, HIV serosorting and transmission risk among men who have sex with men, San Francisco. AIDS 2008, 22(6):787-789.

30. Dougan S, Evans BG, Elford J: Sexually transmitted infections in Western Europe among HIV-positive men who have sex with men. Sex Transm Dis 2007, 34(10):783-790.

31. Heymer KJ, Wilson DP: Available evidence does not support serosorting as an HIV risk reduction strategy. AIDS 2010, 24(6):935-936.

\section{doi:10.1186/1471-2458-13-839}

Cite this article as: Lociciro et al: Men having sex with men serosorting with casual partners: who, how much, and what risk factors in Switzerland, 2007-2009. BMC Public Health 2013 13:839.

\section{Submit your next manuscript to BioMed Central and take full advantage of:}

- Convenient online submission

- Thorough peer review

- No space constraints or color figure charges

- Immediate publication on acceptance

- Inclusion in PubMed, CAS, Scopus and Google Scholar

- Research which is freely available for redistribution 